\title{
Meninos que brincam com bonecas viram meninas? Diferenças de gênero nas brincadeiras de crianças de 4 a 5 anos
}

\author{
Rafaela Junges* \\ Suzana Feldens Schwertner**
}

\begin{abstract}
Resumo
O presente artigo é fruto da pesquisa realizada para o Trabalho de Conclusão de Curso (TCC) de Pedagogia, cujo tema é Gênero na Educação Infantil. Buscou-se conhecer como as crianças interagem com brinquedos trazidos de casa ou presentes na escola, bem como perceber se há diferença na escolha dos brinquedos por meninos e meninas. Além disso, investigou-se se haveria relação entre as cores presentes nos brinquedos e as diferenças de gênero. Trata-se de uma abordagem de cunho qualitativo, uma vez que nos interessam as expressões, movimentos e as falas das crianças em sua singularidade. A metodologia utilizada foi a cartográfica, que permite uma escuta sensível, um olhar atento sobre os territórios a serem investigados. Foram feitas observações e registros das atitudes e reações das crianças nos momentos de brincadeiras na escola, livres ou definidos pela investigação. A pesquisa revelou que a marcação das diferenças de gênero não é proposta pelas crianças, mas pelo meio em que estão inseridas, especialmente pelos pais e pela sociedade em geral. Percebeu-se, também, que a partir do momento em que se coloca a temática em discussão, as crianças parecem entender e questionar os estereótipos de gênero presentes no contexto por meio dos brinquedos. Entendem, igualmente, que o brincar é uma expressão livre, que não precisa ser marcada pelos estereótipos de gênero. Ao final, destacamos que os estudos de gênero merecem mais atenção por parte dos pesquisadores da Educação Infantil e que a temática precisa ser mais discutida por todos os envolvidos.
\end{abstract}

Palavras-chave: Gênero. Educação Infantil. Brinquedos.

* Graduada em Pedagogia pelo Centro Universitário UNIVATES, Lageado/RS.

** Doutora em Educação pela Universidade Federal do Rio Grande do Sul (UFRGS). Professora do curso de Psicologia do Centro Universitário UNIVATES Lageado/RS. 


\title{
Introdução
}

\begin{abstract}
Meninos e meninas de quatro anos exploram fantasias no espaço da sala de aula (vestidos, camisas, saias, gravatas, sapatos, sandálias). A alegria está refletida no rosto de cada um, meninos usando salto alto, não estão preocupados com o que a "sociedade/pais" irão pensar, mas estão interessados no barulho que o salto faz ao tocar o chão, bem como com o equilíbrio que tem que se ter para caminhar com eles. Meninas usando chapéus e gravatas, blazer escuro, dramatizando o papel de pai, policial, "dindo", "ladrão". Sem se preocupar em perder sua "feminilidade", ao exercer esses papeis. No entanto, há olhares desaprovadores, negativos, nos rostos de alguns pais que, por vezes, presenciam estes momentos. ${ }^{2}$
\end{abstract}

Cenas como esta nos preocupam, nos fazem pensar, nos desestabilizam, uma vez que, a partir de uma simples brincadeira, culturalmente, viemos construindo inúmeras projeções a respeito destas pequenas crianças. Sendo assim, começamos a refletir sobre a possibilidade de trabalhar com a temática das diferenças de gênero no Trabalho de Conclusão de Curso. A partir do estudo de diversos autores, como Guacira Lopes Louro (1997), Daniela Finco (2003), Lise Eliot (2013), Claudia Pereira Vianna (2009, 2013), os materiais pesquisados apontaram informações significativas sobre a temática, mostrando múltiplos olhares sobre as diferenças de gênero, apresentando-a como um campo que cada vez mais vem sendo abordado em estudos, e que, no entanto, ainda requer muita investigação. Algumas abordagens envolveram aspectos como: a diferença de gênero nas escolhas dos brinquedos; discussão de gênero através da publicidade vinculada a canais infantis de televisão; diferença de gênero nos objetos decorativos para quartos de crianças; diferença de gênero presente nas histórias infantis.

Para este artigo, perguntamos: de que maneiras as diferenças de gênero vêm sendo apresentadas nos brinquedos das crianças? Como objetivo geral desta pesquisa, pretendeu-se conhecer a maneira como as crianças se relacionam/interagem com brinquedos trazidos de casa ou presentes na escola de Educação Infantil. Como objetivos específicos desta pesquisa, apontamos: perceber se há diferença na escolha dos brinquedos por meninos e meninas; investigar se há relação entre as cores presentes nos brinquedos e as diferenças de gênero; descobrir se existe rejeição das crianças frente a algum tipo de brinquedo disponibilizado; perceber se há predominância de um tipo de brinquedo trazido pelas crianças nos momentos propostos.

Em suma, a escolha deste tema deu-se devido a inquietações nossas em relação à maneira como as questões de gênero vêm sendo interpretadas por pais/mães, professoras e professores e demais indivíduos, mas, principalmente, como essas questões estão sendo interpretadas pelas crianças nos momentos das brincadeiras. 


\section{Gênero: um conceito a ser analisado}

Basta passear de olhos abertos para comprovar que a humanidade se reparte em duas categorias de indivíduos, cujas roupas, rostos, corpos, sorrisos, atitudes, interesses, ocupações são manifestamente diferentes: talvez essas diferenças sejam superficiais, talvez se destinem a desaparecer. O certo é que por enquanto elas existem com uma evidência total. (BEAUVOIR, 1970, p.8).

Já nos anos de 1940, Simone de Beauvoir (1970) destacou que a sociedade estava dividida em duas categorias de gênero - masculino e feminino -, e que estas diferenciavam os indivíduos pelo comportamento, maneira de agir, de se vestir, de brincar. No entanto, Simone cogitou a possibilidade de um dia essas diferenças de gênero desaparecerem. Porém, ao contrário disso, aproximadamente seis décadas depois, essas diferenças ainda são percebidas e cada vez com mais intensidade. Elas estão presentes nos comportamentos de meninos e meninas, nas roupas, nas perfumarias, nas imagens dos pacotes de fraldas para bebês, nas cores, nos brinquedos, nas mídias, nas escolas, no comércio. E diariamente são reforçadas pelos pais, pela sociedade, pelos professores e pelas próprias crianças.

No entanto, a criança não nasce sabendo que pertence ao gênero masculino ou gênero feminino, mas aprende esses conceitos a partir do meio em que está inserida. Ou seja, através da decoração do quarto, dos brinquedos, das roupas e adornos/acessórios, uma vez que, para uma bebê menina, os quartos geralmente são pintados nas cores rosa, lilás, com detalhes delicados e pomposos, com flores, topes, bonecas, pois a sociedade espera que as meninas sejam meigas, carinhosas. Já os quartos de meninos geralmente recebem o azul, o verde como cores predominantes; os brinquedos e presentes que recebem trazem motivos esportivos, como bolas, carrinhos, skate, pois a sociedade espera que os meninos sejam ativos, fortes e corajosos. Sendo assim, dificilmente um quarto de menina será pintado de azul, e dificilmente os meninos terão quarto rosa, com bonecas e artigos de cozinha - tampouco uma composição de tudo isso para ambos.

Sendo assim, "meninos e meninas demostram comportamento, preferências, competências, atributos de personalidade apropriados para seu sexo, seguindo, desde bem pequenos, as normas e padrões estabelecidos" (FINCO, 2003, p. 91). Além disso, de acordo com os "padrões de normalidade" que a sociedade impõe, meninas não podem gostar de jogar futebol, pois o futebol é visto como um esporte masculino - muito embora haja mulheres que se destacam no futebol. E os meninos não podem dedicar-se a ajudar nas atividades de casa, ou brincar com bonecas, pois estas ainda são vistas como atividades pré-determinadas para o gênero feminino. Como anteriormente mencionado, as crianças já nascem imersas nesse meio dividido por diferenças de gênero e desenvolvem seus conceitos de "certo" e "errado" para cada gênero a partir das interações, vivências e situações que presenciam. 
Se, por um lado, meninas podem ter sua identidade de gênero questionada se praticam futebol, com meninos o mesmo ocorre, se eles não o fazem, se não são fanáticos pelo seu time, se não têm um time. Meninos são como que obrigados a gostar de jogar futebol. Pais, mães, amigos, amigas e até educadores/as exercem uma "pressão social" para que pratiquem essa modalidade. Aqueles que não o fizerem podem ser vistos como femininos. (VIANNA; FINCO, 2009, p.278).

Nas vivências das escolas infantis, meninos que procuram brincar com as meninas em brincadeiras de casinha, ou de escolinha, são "diagnosticados" pelas educadoras ou mesmo pelos pais como propensos ao homossexualismo. Sendo assim, muitas vezes essas crianças seguem as condutas preestabelecidas socialmente, deixando de lado os seus desejos, suas curiosidades para não fugir das ações esperadas por cada um.

No entanto, não são as crianças que nascem e já vão determinando com que tipo de brinquedos irão querer brincar, mas são "os pais que constroem o primeiro ambiente de brinquedos da criança, antes que ela comece a fazer suas escolhas" (KISHIMOTO, 2008, p. 210). O gênero já está presente nos brinquedos que a criança encontra em seu meio social. E, a partir destas vivências, ela começa a construção do seu conceito de gênero. No entanto, dificilmente encontraremos em um quarto de menino, bonecas para serem exploradas, muito menos sapatos e bolsas, e, mesmo no quarto de uma menina, seria incomum encontrarmos carrinhos de corrida, bonequinhos de super-heróis, entre outros. No entanto, Eliot (2013) deixa claro em seu livro que:

[...] os meninos humanos se interessam por bonecas tanto quanto as meninas até os 12 meses. [...] É possível, portanto, que meninos e meninas, ambos, comecem gostando de bonecas - assim como a maioria dos bebês prefere instintivamente o rosto humano a estímulos inanimados -, mas depois, durante o segundo ano de vida, quando aumenta seu nível de atividade e fisicalidade, os meninos sejam atraídos por bolas e veículos (ELIOT, 2013, p.132).

No entanto, ao preferir ou mesmo brincar com brinquedos definidos por padrões sociais como “inadequados” para seu gênero, esta ação irá desencadear preocupações, medos, angústias nos pais que presenciam estes momentos, uma vez que muitas vezes ouvimos, por exemplo, que, a partir da brincadeira com bonecas, o menino irá se tornar "gay". Por que, ao invés do medo da homossexualidade, não se vê, em tal situação, a possibilidade de os meninos se tornarem pais que cuidam de seus filhos?

Muitas vezes, quando a criança encontra-se nos seus momentos de brincadeira, de exploração, de ludicidade, ela interpreta, cria, não se importando se a brincadeira que desenvolve está certa ou errada. Durante esse momento, a criança é livre para viver aquele momento de todas as formas 
possíveis. Emoções, tristeza, angústia, alegria, entusiasmo, encantamento, paixão são alguns dos sentimentos que as crianças podem vir a sentir durante o ato do brincar livre. No entanto, muitas vezes este brincar é mal interpretado por aqueles que o veem.

Indo ao encontro desta afirmação, Eliot (2013) ressalta que:

Os pais reagem diferentemente aos tipos de brinquedos que as crianças parecem apreciar. Sutilmente ou não, eles dissuadem os filhos de brincar com brinquedos femininos e, em menor extensão, as filhas com brinquedos masculinos. [...] os pais respondem mais positivamente quando a criança escolhe um brinquedo adequado ao seu gênero, por exemplo, quando o menino pega o martelo e a menina empurra um carrinho de compras. (ELIOT, 2013, p.134).

E não são apenas os pais que reagem de forma negativa quando presenciam estas cenas, mas também os professores e professoras, cuidadores(as), entre outras pessoas que muitas vezes passam um longo período do dia com estas crianças. Sendo assim, cabe a esses indivíduos, que fazem parte do meio social da criança, conhecer, estudar, discutir, debater, investigar as diferenças de gênero. Em relação à escola, conforme assevera Browne:

Os profissionais precisam refletir sobre como suas práticas e atendimentos são moldados por discursos que influenciam expectativas em relação ao comportamento das crianças e respostas adultas às crianças. [...] $\mathrm{O}$ desafio, para o profissional, é fornecer oportunidades para as crianças explorarem formas diversas de feminilidade $\mathrm{e}$ masculinidade. (2010, p.83).

O gênero está presente nas escolas e pode ser encontrado nas filas de menino e menina; nos banheiros para menino e banheiros para meninas; nos brinquedos para meninos e brinquedos para meninas; nas aulas de Educação Física, nas quais meninos jogam bola e meninas conversam ou pulam corda, entre outros inúmeros exemplos que poderiam ser aqui citados. No entanto,

[...] se admitirmos que a escola não apenas transmite conhecimento, nem mesmo apenas os produz, mas que ela também fabrica sujeitos, produz identidades étnicas, de gênero, de classe, se reconhecemos que essas identidades então sendo produzidas através de relações de desigualdades; se admitirmos que a escola está intrinsecamente comprometida com a manutenção de uma sociedade dividida e que faz isso cotidianamente, com nossa participação ou omissão; se acreditarmos que a prática escolar é historicamente contingente e que é uma prática política, isto é, que se transforma e pode ser subvertida; e, por fim, se não nos sentimos conformes com essas divisões sociais, então, certamente, encontramos justificativas não apenas para observar, mas, especialmente, para tentar interferir na continuidade dessas desigualdades. (LOURO, 1997, p.85).

Assim sendo, cabe aos pais, professores, entre outras pessoas, investigar, estudar, observar, refletir e principalmente mudar as práticas cotidianas que vêm sendo construídas a favor da manutenção dos estereótipos de gênero no interior das escolas de Educação Infantil. 


\section{METODOLOGIA}

A presente pesquisa teve uma abordagem de cunho qualitativo, uma vez que se pretendeu observar as atitudes e reações das crianças em momentos de brincadeiras na escola.

Além disso, optamos em seguir o método cartográfico, já que:

A cartografia como método de pesquisa-intervenção pressupõe uma orientação do trabalho do pesquisador que não se faz de modo prescritivo, por regras já prontas nem com objetivos previamente estabelecidos. No entanto, não se trata de uma ação sem direção, já que a cartografia reverte o sentido tradicional de método - não mais um caminhar para alcançar metas pré-fixadas [...] mas o primado do caminhar que traça no percurso suas metas. (PASSOS; KASTRUP; ESCÓSSIA, 2009, p.17).

Dessa forma, a partir da realização desta pesquisa, observamos e registramos as falas das crianças pertencentes a uma turma da faixa etária de 4 a 5 anos de uma escola municipal de Educação Infantil, de um município no interior do Rio Grande do Sul, durante os momentos de brincadeiras com brinquedo livre. Por brinquedo livre entende-se, por exemplo, o brinquedo que as crianças trazem de suas casas, tais como: carrinhos, bonecas, peças de encaixe, animais de plástico, roupas, acessórios, blocos de madeira, blocos construtores, quebra-cabeças, dominós, bichos de pelúcia, sucatas, entre outros. Além disso, através do olhar cartográfico realizamos intervenções, questionando, propondo, interagindo. A turma investigada era o Nível E2 desta escola, com 19 alunos; dez meninos e nove meninas.

Para a realização da pesquisa, propusemos quatro momentos de brincadeiras com essa turma de crianças, sendo eles:

$1^{\circ}$ momento: exploração de brinquedos livres trazidos de casa (Dia do Brinquedo na escola);

$2^{\circ}$ momento: exploração de um brinquedo solicitado (o brinquedo que a criança mais gosta);

$3^{\circ}$ momento: exploração de bonecas e acessórios pela turma (Barbies, bebês, etc.);

$4^{\mathrm{o}}$ momento: exploração de carrinhos, motos, caminhões, escavadeiras, pela turma;

Vale ressaltar aqui que, como se trata de uma turma de Educação Infantil, a frequência das crianças nesta etapa da Educação Básica não é obrigatória. Sendo assim, as crianças que estavam ausentes durante os momentos, não participaram da pesquisa.

O território da sala de aula foi habitado de maneira minuciosa, detalhada, uma vez que:

Como cartógrafos, nos aproximamos do campo como estrangeiros visitantes de um território que não habitamos. O território vai sendo explorado por olhares, escutas, pela 
sensibilidade aos odores, gostos e ritmos. [...] fomos a campo para estar junto e participar daquilo que acontece naquela comunidade; para conhecer com a cognição ampliada, isto é, aberta ao plano dos afetos (PASSOS; KASTRUP; ESCÓSSIA, 2009, p.63).

Como estrangeiras desta pesquisa, procuramos conhecer o ambiente, bem como quem o habita, procuramos também observar, refletir, retornar, ingressar, transcrever, reescrever, reinventar, intervir, sobre eles através deste "movimento contínuo" (PASSOS; KASTRUP; ESCÓSSIA, 2009, p. 59). Além disso, buscamos, através de uma escuta sensível, atentar-nos a detalhes antes não percebidos, olhar para aquelas crianças de outros ângulos, "com outros olhos", não os vês apenas como alunos, mas como sujeitos singulares, repletos de potencialidades.

Inicialmente sentamos com as crianças para uma conversa e foram explicadas as intenções da pesquisa. Ressaltamos ainda que contaríamos com a ajuda de todos para a realização desse trabalho. Os termos de compromisso que foram assinados pelos responsáveis, bem como o termo de assentimento de menor, que foi elaborado especialmente para as crianças assinarem, foram respectivamente lidos e esclarecidos.

O momento da assinatura foi o mais esperado por todos, pois poderiam usar a caneta da professora. Algumas crianças não lembravam todas as letras presentes no nome; diante disso, utilizaram a ficha do nome ${ }^{3}$ para apoio. As crianças mostraram-se surpresas e ao mesmo tempo empolgadas com a pesquisa que seria realizada.

Em seguida brincamos com as crianças com um aplicativo para gravação de áudio, ou seja, um gravador. Iniciamos falando nossos nomes e passamos o aparelho para as crianças falarem os seus. Quando todos falaram, o áudio foi reproduzido para todos escutarem. Ouvimos a gravação atentamente, em silêncio, mas a cada nome falado, os rostos se transformavam em sorrisos. A brincadeira levou mais de uma hora, as crianças ficaram fascinadas com o gravador. Durante a exploração, uma das meninas da turma questionou: "Ele grava? Tudo mesmo? Como ele grava? Deixa eu ver ele."

E quando a brincadeira findou, pois estava próximo da hora de uma das refeições, todos lamentaram, pois queriam brincar mais.

O primeiro momento da pesquisa foi realizado no dia 25 de agosto de 2014, segunda-feira, dia em que as crianças podem trazer um brinquedo ${ }^{4}$ da sua casa. À medida que as crianças chegavam, organizavam seus materiais e iam brincar com seus brinquedos de maneira livre, e já nesta primeira parte de recepção nos aproximamos com o gravador e conversamos com elas sobre os brinquedos que haviam trazido. E, logo no início, foi possível perceber que algumas delas mostravam-se envergonhadas para falar, pois prontamente percebiam a presença do aparelho gravador. No entanto, ao 
ver os demais colegas conversando, não se importaram mais. Esse primeiro momento durou aproximadamente uma hora.

O segundo momento de brincadeiras foi realizado no dia 3 de setembro de 2014, quarta-feira. Para este momento, foi solicitado que as crianças trouxessem o brinquedo que mais gostavam de brincar. E, para isso, elaboramos um bilhete solicitando aos responsáveis ${ }^{5}$ que mandassem o brinquedo, uma vez que este iria ser usado apenas para a pesquisa e após seria guardado na mochila da criança. Assim como no primeiro momento, as crianças foram chegando com seus brinquedos e explorando-os livremente, e aos poucos nos aproximamos delas para conversar e brincar.

Após o momento de exploração livre dos brinquedos que mais gostam de brincar, organizamos as crianças em duas fileiras, uma de frente para outra. Uma fileira de meninas e uma de meninos. Cada criança estava com seu brinquedo favorito em mãos e então solicitamos que elas trocassem os brinquedos com as crianças da fila em frente, ou seja, meninos trocam com meninas, meninas trocam com meninos. Muitas crianças não gostaram da ideia, ainda que tivéssemos ressaltado que seria por pouco tempo; no entanto, as meninas não se importaram em brincar com os brinquedos que os meninos trouxeram, bem como muitos meninos não se importaram em explorar os brinquedos das meninas.

O terceiro momento de exploração dos brinquedos foi realizado no dia 9 de setembro de 2014 . Neste dia, solicitamos que as crianças se organizassem em rodinha; no centro da roda, diferentes brinquedos, pré-determinados pela sociedade como "brinquedos de menino": carrinhos, caminhões, patrolas, motos, pistas, posto de gasolina, por exemplo.

Inicialmente conversamos com as crianças sobre os brinquedos ali presentes, questionando-as sobre o que eram, quem poderia brincar com eles, quem tinha algum deles em casa. Durante o relato das crianças, percebeu-se que aquelas meninas que tinham carrinhos em casa haviam ganhado de presente das avós ou não lembravam quem lhes havia dado. Nenhuma das meninas presentes respondeu que havia solicitado aos pais um carrinho; no entanto, todas mostraram interesse em tê-los em casa para brincar. A turma mostrou-se mais interessada no posto de gasolina e nas pistas. No momento de exploração, meninos e meninas apostavam corridas para ver quem chegava mais rápido ao outro lado da sala. Esse momento teve aproximadamente uma hora de duração, ocorrendo das $9 \mathrm{~h}$ às $10 \mathrm{~h}$ da manhã.

O quarto e último momento de exploração de brinquedos para a pesquisa aconteceu no dia 16 de setembro de 2014, terça-feira. Para esse dia, solicitamos que a turma se organizasse livremente na sala, ressaltando que iríamos buscar um brinquedo para eles explorarem. Quando retornamos à sala, ao se 
depararem com a mesa repleta de bonecas, as crianças reagiram com surpresa, mas ao mesmo tempo com animação: “Oba, bonecas”!, exclamavam. Ao questionarmos alguns meninos sobre a possibilidade de brincar com bonecas, todos responderam de maneira positiva; um deles ainda enfatizou que poderia brincar com bonecas, pois era um brinquedo.

Durante esse primeiro momento percebeu-se que ninguém se opôs a explorar as bonecas. No entanto, os meninos procuraram brincar com as bonecas vestidas com roupas azuis, dizendo que se tratava de bebês meninos; diferente das meninas, que estavam sentadas "nanando" as bonecas, de maneira tranquila, os meninos ensaiavam saltos com suas bonecas em uma piscina imaginária.

As falas das crianças foram gravadas e transcritas, resultando em 38 laudas riquíssimas de conversas de meninos e meninas. A partir desse material foi feita uma seleção das falas mais significativas quanto às diferenças de gênero para posterior análise. Durante a transcrição, utilizamos as letras inicias do nome das crianças que participaram da pesquisa, como forma de organização; no entanto, optamos em diferenciar as meninas com letras em negrito e os meninos em fonte comum ${ }^{6}$. Vale ressaltar aqui que a letra $\mathrm{P}$ representa a professora/pesquisadora.

\section{RESULTADOS E DISCUSSÕES}

Em um contexto de Educação Infantil, falas direcionadas às diferenças de gênero são bastante comuns, uma vez que, de acordo com Souza (2008),

[...] desde o nascimento, as crianças se deparam com um mundo estruturado pelas representações e são com estas que elas se desenvolverão. Confirmar a identidade significa dizer "o que somos" e "o que não somos", sempre manifestando distinções. (SOUZA, 2008, p.154).

Sendo assim, meninos aprendem desde bebês que devem brincar com carrinho, e meninas aprendem que devem brincar com bonecas. Em decorrência, as crianças usam dessas falas para diferenciar os brinquedos e brincadeiras como brinquedo e brincadeiras "de menino" e brinquedos e brincadeiras "de menina". Tal como na pergunta que uma menina fez a outras durante o momento de exploração do brinquedo de casa:

LA - E se for uma corrida de cavalo de menina?

O que será que difere uma corrida de cavalos de meninos e uma corrida de cavalos de meninas? A cor dos cavalos? A cor das roupas utilizadas pelas competidoras? O fato de ser um momento só de meninas? A velocidade que os cavalos alcançam? O público que estará assistindo? 
Falas como essa nos instigam a refletir sobre o que as crianças pensam sobre estas diferenças de gênero. Na próxima cena, as crianças, neste caso, meninas, esclarecem que meninos não podem ter brilho na roupa, pois não são meninas:

$\mathrm{P}-\mathrm{E}$ as roupas dos meninos aqui (mostrando uma blusa) também têm brilho?

(As meninas presentes na rodinha respondem juntas "Nãããooo!")

$P$ - Por que não?

$A C$ - Porque eles são príncipes, eles não são meninas.

Conforme o diálogo acima, as roupas com brilho são relacionadas ao gênero feminino; sendo assim, seriam impróprias para o gênero masculino, no caso, o príncipe ${ }^{7}$. De acordo com Paz (2008),

[...] os meninos são controlados, desde os primeiros anos escolares, para que tenham atitudes de acordo com o modelo de masculinidade idealizada, valorizada, predominante, ou seja, heterossexual, viril, corajosa, impetuosa, vivaz, entre outras características consideradas naturalmente masculinas. Ensina-se desde cedo que menino não chora, que menino não sente dor e, expressões de afetividade entre eles, não são incentivadas. Existe uma maneira como eles devem agir, de forma que se distanciem do comportamento das meninas. (PAZ, 2008, p.3).

Por conseguinte, de acordo com o que os padrões de gênero que a sociedade espera dos indivíduos, não seria "adequado" os meninos utilizarem roupas com brilho, pois este artefato remete ao glamour, à sofisticação, que são atributos voltados para o gênero feminino - mesmo no papel de príncipes.

Espaços, roupas, perfumaria, brinquedos: tudo está visivelmente separado quanto ao gênero masculino e gênero feminino. Em relação aos brinquedos, encontramos uma vasta diversidade tanto para meninos quanto para meninas. Estes brinquedos se diferem pelas cores, modelos, tipo e localização, uma vez que as próprias lojas que comercializam estes tipos de materiais organizam os produtos quanto ao gênero ao qual fazem parte. Desse modo, brinquedos de meninos e brinquedos de meninas, bem como roupas de menino e roupas de menina, nunca estarão misturados; estarão dispostos de maneira que seja visível e bem delimitado o que é “adequado" para cada gênero brincar ou usar. E sempre que uma criança, independente do gênero ao qual pertença, tender a procurar um artigo tido como do gênero oposto, rapidamente será "corrigida" pelos pais, professores, vendedores, bem como pelas pessoas que fazem parte de seu convívio.

Frente a isso, Eliot (2013) destaca que

[...] os pais respondem mais positivamente quando a criança escolhe um brinquedo adequado ao seu gênero, por exemplo, quando o menino pega um martelo e a menina empurra um carrinho de compras. E é mais provável que fiquem arrepiados quando a 
criança brinca com o tipo "errado" de brinquedo - o menino abraça uma boneca ou a menina brande uma espada. Os pais (homens) reagem mais fortemente que as mães, especialmente quando veem o filho em alguma brincadeira tipicamente feminina. (ELIOT, 2013, p.134).

Sendo assim, raramente encontramos meninas explorando brinquedos ditos de meninos, ou meninos explorando brinquedos ditos de meninas, pois a sociedade predetermina com o que a criança pode ou não brincar, lembrando que são os pais que constroem o primeiro ambiente de brinquedos da criança (KISHIMOTO, 2008). Como podemos ver na cena a seguir, no primeiro momento de exploração de brinquedos livres:

ER - E o pai trouxe a geladeira da Peppa $^{8}$ pra minha mana.

(o som do carro torna-se mais alto quando ele se aproxima do gravador)

$\mathrm{P}-\mathrm{O}$ que ele deu?

ER - A geladeira da Peppa pra mana.

$\mathrm{P}$ - Por que ele não deu um carro pra mana?

ER - Porque não!

ER - É que é de menina.

Meninos são presenteados com determinados brinquedos e meninas com brinquedos que se distinguem dos brinquedos de meninos, assim como podemos observar na cena descrita. O pai presenteou o filho com um carrinho que, ao ser ligado, imitava uma furadeira, e na direção deste havia um homem com uniforme de operário. Já a filha foi presenteada com uma geladeira da Peppa, que pode ser relacionada à vida doméstica, aos cuidados com o lar. Ao questionarmos este menino sobre o porquê da irmã não ter ganhado um carrinho também, ele rapidamente deixou claro que era uma menina, sendo assim, não poderia ganhar carrinhos de presente, e a geladeira seria o presente correto a ser dado 9 .

Sendo assim, de acordo com Eliot:

[...] embora, fatores inatos claramente inclinem meninos e meninas para diferentes tipos de brinquedos, também há muitas evidências de que essas escolhas são bastante reforçadas pelos pais, pelos pares, e especialmente, por sua própria percepção emergente de ser menino e ser menina. (2013, p.133).

$\mathrm{Na}$ cena a seguir, outro assunto muito importante foi colocado em discussão pelas crianças: mulheres podem ou não podem dirigir? Podem dirigir qualquer meio de transporte?

$\mathrm{P}$ - Só os meninos dirigem?

$\mathrm{H}-\mathrm{Sim}$ e as meninas...

$\mathrm{P}-\mathrm{Ah}$, as meninas também?

VI - As meninas dirigem moto e carro também!

$\mathrm{P}$ - E caminhão não?

AC - Sim, eu já vi caminhão... uma guria dirigindo caminhão! 
$\mathrm{P}-\mathrm{E}$ as meninas podem dirigir essas máquinas?

ER - Não!

(Várias crianças gritam "sim” ao mesmo tempo)

$\mathrm{P}$ - Vamos ver o que o ER acha....

ER - Não!

$\mathrm{P}-$ Por quê?

ER - Porque não!

$\mathrm{P}$ - Só os meninos podem dirigir máquinas?

LA - Menina também.

Feminino. Mulheres. Veículo. Direção. Esse é um preconceito que muitas pessoas propagam: "Mulheres não sabem dirigir", "mulher não pode dirigir". No entanto, quem determina que as mulheres não podem, ou mesmo não sabem dirigir, se elas têm de passar pelos mesmos testes que os homens na autoescola para receber a permissão para isso? Refletindo a respeito, o que estamos ensinando para as crianças? Muitas vezes, as crianças convivem em um meio social onde a mulher não dirige, apenas a figura masculina é relacionada ao carro, moto, máquina. Porém, ao questionarmos as outras crianças que estavam próximas da rodinha sobre a possibilidade de a mulher dirigir qualquer tipo de veículo, muitos ressaltaram que elas não só podiam dirigir como também que já haviam visto mulheres dirigindo até caminhão.

Frente a essa cena, foi possível perceber que as meninas mostram-se mais esclarecidas frente às questões relacionadas às diferenças de gênero que surgem em suas conversas. Como podemos observar na cena que segue, na qual uma menina conversa sobre o brinquedo que trouxe de casa: um carro.

$\mathrm{P}$ - Eu quero brincar com esse carrão, depois, também.

AL - Ele é um Fusca!

$\mathrm{P}$ - Um Fusca! Que lindo teu Fusca! Que cor ele é?

AL - Rosa

$\mathrm{P}-$ Quem te deu?

AL - A Júlia

$\mathrm{P}$ - É?! E tu gosta do teu carro?

AL - (Faz sinal afirmativo com a cabeça).

$\mathrm{P}-$ Que legal, eu adorei ele...

Qual o problema de uma menina de quatro anos preferir trazer um carro (e ainda rosa...) para brincar na escola ao invés de uma boneca? Para a mãe dessa menina, isso é um grande problema, uma vez que, diversas vezes, já orientou a menina para que trouxesse "brinquedos de menina" para a escola. Em uma dessas orientações, a mãe utilizou a seguinte comparação: bola e carro são brinquedos de menino e boneca é um brinquedo de menina. Mesmo assim, a menina insiste em trazer seus brinquedos favoritos, ainda que contra a vontade da mãe. 
Conversando com essa menina sobre seu fusca rosa, foi questionado sobre quem havia lhe presenteado com o carro e esta respondeu que foi sua mãe. Além do carro, a menina também ressaltou que possui uma bola rosa, que recebeu de lembrança da festa de aniversário de sua prima.

Frente a isso, Cruz, Silva e Souza (2012) destacam que:

Carros são objetos pensados e criados para o masculino, mas quando se estende para ao feminino o carro precisa ser "feminizado", necessita fazer parte do universo tipicamente feminino: um carro delicado, com cores variando entre o rosa, o roxo e o lilás. O carro de menina não é pensado como sendo um carro de menino. Menina quando pode brincar ou gostar de carro, este precisa entrar em seu campo de materialização do feminino (CRUZ; SILVA; SOUZA, 2012, on-line).

Sendo assim, a sociedade estipula que as meninas podem, sim, ter brinquedos ditos "de meninos" desde que estes estejam caracterizados como "brinquedos de meninas", seja através das cores, dos formatos, do estilo.

No entanto, a partir do terceiro momento de brincadeiras, quando se tratava da exploração de carros, motos, patrolas, caminhão, foi possível perceber o interesse de muitas meninas em relação a estes brinquedos, independente da sua cor, do seu formato. Na cena que segue, a menina trouxe à tona uma fala bastante usada por meninos e meninas:

P - São esses carrinhos assim que tu tem? (mostrando para ela os carrinhos de ferro, tipo Hot Wheels ${ }^{10}$ ).

VA - Não.

$\mathrm{P}$ - Como é que ele é?

VA - Ele é vermelho feio.

$\mathrm{P}-\mathrm{Hum} .$. Quem te deu ele?

VA - Não sei. Eu tinha quando eu era bebê, eu acho que eu virei menino quando eu era bebê.

A crença de que ao explorar um brinquedo direcionado ao gênero oposto a criança irá "virar menino" ou "virar menina" é muito comum. No entanto essa crença não nasce com as crianças. De acordo com Eliot (2013):

Existe uma razão muito simples para os pais hesitarem em promover o brincar não tradicional: o medo! As mães poderiam se preocupar: "Meu filho já é tão apegado a mim. Se eu deixar brincar com bonecas e com os meus sapatos de salto, será que isso não afetará sua masculinidade? Isso não o tornará gay?” A resposta é não. (ELIOT, 2013, p.135).

As próprias crianças demostram esse "medo" em suas brincadeiras, pois são vigiadas constantemente para não cruzarem as fronteiras de gênero (FINCO, 2010). Como podemos ver na cena 
a seguir, durante o segundo momento de brincadeiras, foi proposta uma troca de brinquedos entre meninos e meninas, e um dos meninos recebeu uma boneca:

$\mathrm{H}$ - Ah, eu não vou brincar com boneca!

$\mathrm{P}$ - Por que não?

$\mathrm{H}$ - Porque daí eu vou virar menina.

$\mathrm{P}$ - Como assim? Quem disse que tu vai virar menina?

$\mathrm{H}-\mathrm{O} \mathrm{HE}$.

$\mathrm{P}$ - Mas será que isso vai acontecer?

$\mathrm{H}-\mathrm{Sim}$.

$\mathrm{P}$ - Mas como isso acontece? É tipo uma mágica? Tu brinca com a boneca e vira menina?

$\mathrm{H}-\mathrm{E}$.

$\mathrm{P}$ - Então vamos fazer o teste, pega a boneca pra ver se alguma coisa acontece.

MA - Isso, pega.

$\mathrm{H}$ - Não quero, eu quero brincar com o meu.

A vontade de explorar aquela boneca poderia ser gigante, mas o que os outros colegas iriam pensar? Um menino brincando com bonecas? Um menino pode brincar com bonecas? Meninos que brincam com bonecas viram meninas? Como? Surge o medo de se tornar o que não se é, o que não se deve ser? Parece haver algo errado ou confuso e que deve ser evitado. Ao ser questionado sobre como o menino se transformaria em uma menina caso explorasse a boneca, ele não soube responder. No entanto, também não quis experimentar, preferindo montar o seu quebra-cabeça.

Frente a isso, Vianna e Finco (2009) deixam claro que:

Meninos e meninas desenvolvem seus comportamentos e potencialidades no sentido de corresponder às expectativas quanto às características mais desejáveis para o que é definido como pertinente a um modelo singular e unívoco de masculinidade e de feminilidade em nossa sociedade. (VIANNA; FINCO, 2009, p. 279).

Em outra cena transcrita, a turma se prepara para explorar as bonecas disponibilizadas para o terceiro momento da pesquisa, quando os meninos percebem que existem "bonecas-meninos". De acordo com eles, as bonecas-meninos são as que possuem roupas azuis, bonés, uma vez que não tinham conhecimento do corpo escondido sob as roupas da boneca:

$$
\begin{aligned}
& \text { ER - É um menino. } \\
& \mathrm{P} \text { - Como? } \\
& \text { ER - É, meninos. } \\
& \mathrm{P} \text { - Meninos? } \\
& \text { MA - Esse ali (apontando para os/as bonecos/as vestidos/as com roupas azuis). } \\
& \text { VI - O menino que tem um boné. }
\end{aligned}
$$


Em um primeiro momento, os meninos exploraram apenas as "bonecas-meninos". Corriam, fazendo as "bonecas-meninos" voar pelo ambiente da sala de aula e saltar em piscinas imaginárias. No entanto, isso não os impediu de se reunirem com as meninas e auxiliá-las nas trocas de roupinhas e fraldas das demais bonecas. No final da exploração, todos, meninas e meninos, brincavam com diferentes tipos de bonecas, sem se importar com qual gênero o brinquedo se associava.

Após a brincadeira, em um momento de reflexão, as crianças perceberam que não deixariam de ser menino ou menina se brincassem com determinado tipo de brinquedo "adequado" ou não para o seu gênero, pois se trata apenas de brinquedos. Como podemos ver na cena que segue:

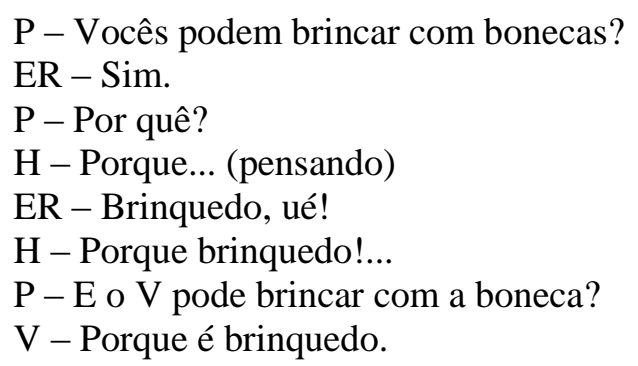

Após essa reflexão, a turma passou a explorar os diferentes tipos de brinquedos na escola sem fazer distinção de gênero. No entanto, quando se trata do ambiente familiar, as crianças muitas vezes nem esperam que os pais lhes presenteiem, ou mesmo que lhes permitam explorar brinquedos “adequados" para o gênero oposto, ou, ainda, os pais desconhecem o desejo da criança em possuir determinados brinquedos, como podemos analisar na cena que segue, ocorrida no último momento de exploração:

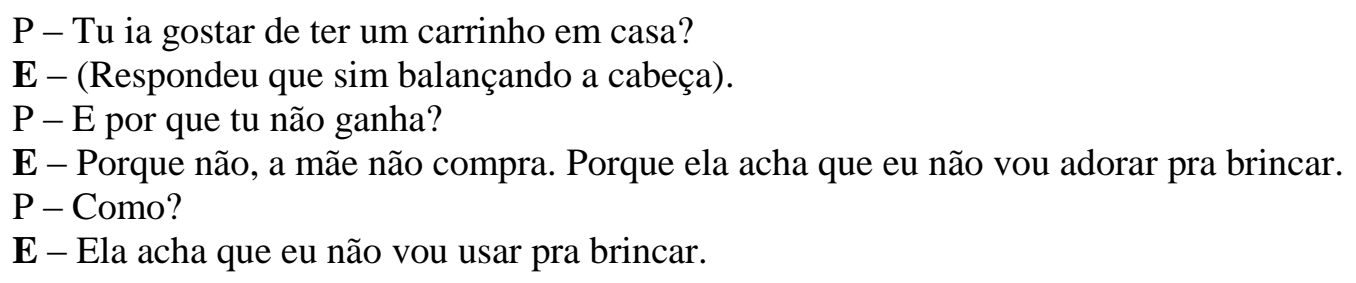

Pais, professores, responsáveis e a sociedade em geral limitam as crianças através de estereótipos, construindo um ambiente de brinquedos correspondente ao gênero a que esta pertence. Sendo assim, a criança cresce acreditando nas possibilidades de brincadeiras que estão presentes no seu contexto e deixa de explorar brinquedos indicados para o gênero oposto, mesmo esses sendo de grande importância para seu desenvolvimento.

Frente a isso, Eliot (2013) destaca:

Os pais de meninos devem prestar atenção, porque brincar com bonecas ou cuidar de bebês trazem muitos ganhos. Brincar de boneca e encenar os papéis de pai e mãe 
reforça habilidades sociais e emocionais: cuidar de outras pessoas, levar em conta suas necessidades e atendê-las, bem como perceber o que elas estão sentindo. (ELIOT, 2013, p.155).

Assim como os pais de meninas também devem permitir que elas explorem brinquedos ditos de “menino", como bolas, carrinhos, espadas, pois eles desenvolvem a coordenação motora, a agilidade, a atenção, a força, a afirmação entre tantas outras habilidades bem-vindas e necessárias aos seres humanos, independentemente de sua condição de gênero.

\section{CONSIDERAÇÕES FINAIS}

Por meio desta pesquisa, percebemos que a temática "diferenças de gênero" vem ganhando mais espaço no meio acadêmico. A pesquisa bibliográfica mostrou que muitas são as possibilidades de investigação, muitos são os olhares e leituras a respeito destas diferenças. No entanto, ainda há muito a ser investigado, por exemplo, qual a opinião das crianças sobre as diferenças de gênero; o que os pais pensam sobre as diferenças de gênero; qual a visão das(os) profissionais da Educação em relação a esta temática, já que cada vez mais os estereótipos de gênero estão sendo realçados ao invés de serem atenuados e colocados em discussão. Os interesses mercadológicos não podem ser menosprezados na construção e reforço do que quer que seja dito como de menino e/ou de menina.

Percebemos que as diferenças de gênero interferem de maneira determinante no desenvolvimento das crianças, pois agem como uma forma de limitação de suas ações, entre o que é tido como "certo" e "errado" para cada gênero. Essas marcações das diferenças de gênero não são propostas pelas crianças, mas pelo meio em que estão inseridas, especialmente pelos pais, pela mídia, a indústria e o comércio.

No entanto, quando foi possibilitado às crianças um momento de reflexão sobre as ideias do que seria menino e menina, brinquedo de menino e brinquedo de menina, elas passaram a compreender e identificar estereótipos de gênero impostos socialmente, ressaltando ainda que não passavam de “mentiras que 'alguéns' inventam”. Podemos considerar essa reflexão como o grande marco do nosso trabalho.

Não estamos afirmando que as diferenças de gênero não sejam importantes; elas são, especialmente nesta faixa etária em que as crianças se encontram, entre os quatro e cinco anos de idade. No entanto, a forma como estamos estabelecendo essas diferenças faz com que construamos ambientes 
preconceituosos, que determinam e reforçam estereótipos de gênero, além de limitarem as ações e especialmente o livre brincar das crianças.

Sendo assim, nosso papel como acadêmicas(os), pesquisadoras(es) e/ou professoras(es) é proporcionar momentos de reflexão a respeito de como a temática "Diferenças de Gênero" está sendo investigada nas famílias, nas salas de aula, no meio em que vivemos ou mesmo o que podemos fazer no intuito de contribuir para o desaparecimento dos estereótipos de gênero que nos cercam em todos os momentos.

Além disso, é imprescindível possibilitar às crianças explorações de diferentes tipos de brinquedos, não apenas os brinquedos prescritos como "adequados" para cada gênero, mas brinquedos que proporcionem momentos prazerosos, de diversão, de exploração saudável, em que o brincar seja a única palavra de ordem e os estereótipos de gênero não existam.

\section{Notas}

${ }^{1}$ A utilização de aspas foi sugerida posteriormente, por entender que se trata de conceito em discussão quando se estuda gênero.

${ }^{2}$ Cena retirada do diário de campo das pesquisadoras. O diário de campo serviu como ferramenta imprescindível de registro de situações e falas das crianças em relação à temática Gênero. As cenas aparecerão ao longo do texto, em fonte itálica, a fim de destacar o momento, diferenciado do texto do artigo.

${ }^{3}$ As fichas do nome são compostas por retângulos de cartolina com o nome das crianças em letra bastão, elaboradas pelas professoras da turma.

${ }^{4}$ Conforme cronograma da turma, nas segundas-feiras, cada criança pode trazer um brinquedo de casa para explorar. Este retorna para casa no final do dia.

${ }^{5}$ Vale ressaltar que a figura materna ou apenas feminina não deve ser a única responsável pela criança quando se trata de assuntos escolares. A figura masculina também tem papel fundamental na vida escolar da criança. Durante a pesquisa, percebemos que os pais (figura masculina) se mostraram bastante interessados pela investigação, fazendo questionamentos e apresentando suas dúvidas à medida que elas surgiam.

${ }^{6}$ Vale destacar que este foi apenas um modo encontrado para identificar com mais facilidade quando a fala era de um menino ou de uma menina.

${ }^{7}$ Note-se que prontamente os meninos são colocados, nas histórias de reinos encantados, no lugar de príncipes. O reino dos contos de fadas, permeado por príncipes (meninos) e princesas (meninas), por histórias de romances entre este casal perfeito, que terminam com "E foram felizes para sempre..." seguem ocupando espaço importante na fantasia das crianças.

${ }^{8}$ Mais conhecida como "Peppa Pig"; é uma porquinha cor-de-rosa, personagem principal de um desenho animado no qual a maioria dos personagens do núcleo familiar são porcos.

${ }^{9}$ Vale destacar que vivemos em um tempo em que as mulheres vêm conquistando cada vez mais espaços que antes eram ocupados quase que exclusivamente por homens. Contudo, ao pensar sobre a relação mulheres e automóveis, podemos inferir que há tempos elas se tornaram alvo importante da indústria automobilística, sendo escutadas pelas montadoras acerca de suas preferências ao serem as responsáveis por uma parcela cada vez maior da compra de automóveis. Parece que esta atualização ainda merece atenção nas brincadeiras infantis. 
${ }^{10}$ Marca de carrinhos de brinquedo em miniatura feitos de ferro. Podem ser colecionáveis, pois sua diversidade abrange desde réplicas de carros antigos a esportivos modernos variados.

\section{REFERÊNCIAS}

BEAUVOIR, Simone de. Segundo Sexo. v 1. São Paulo: Difusão Europeia do Livro, 1970. Disponível em: <http://brasil.indymedia.org/media/2008/01/409660.pdf> Acesso em: 5 maio 2015.

BROWNE, Naima. A identidade e as crianças como aprendentes. In: MOYLES, Janet. Fundamentos da educação infantil: enfrentando o desafio. Porto Alegre: Artmed, 2010, p. 70-85.

CRUZ, Liliane Moreira; SILVA, Zenilton Gondim; SOUZA, Marcos Lopes de. O brinquedo e produção do gênero na educação infantil: uma análise pós-estruturalista. In: SEMINÁRIO NACIONAL DE EDUCAÇÃO, DIVERSIDADE SEXUAL E DIREITOS HUMANOS, 2. 2012, Vitória. Anais eletrônicos... Disponível em: <http://www.periodicos.ufes.br/gepss/article/download/3880/3095> Acesso em: 23 out. 2015.

ELIOT, Lise. Cérebro azul ou rosa. O impacto das diferenças de gênero na educação. Porto Alegre: Penso, 2013.

ELIOT, Lise. Entre o rosa e o azul. (Entrevista) Revista Pátio Educação Infantil. Porto Alegre, Ano XV, n. 36, p.16-18, jul./set. 2013.

FINCO, Daniela. Os perigos da naturalização das relações sociais na Educação Infantil. Revista Pátio Educação Infantil. Porto alegre, ano XV, nº 36, p. 4-7. jul./set. 2013.

FINCO, Daniela. Relações de gênero nas brincadeiras de meninos e meninas na educação infantil. ProPosições, $\quad$ v. $14, \quad$ n. $\quad 3, \quad$ set./dez. $2003 . \quad$ Disponível em: http://www.proposicoes.fe.unicamp.br/proposicoes/textos/42-dossie-fincod.pdf. Acesso em: 23 out. 2015.

KISHIMOTO, Tizuko Morchida; ONO Andréia Tiemi. Brinquedo, gênero e educação na brinquedoteca. Pro-Posições, v. 19, n. 3, set./dez. 2008. Disponível em: <http://www.scielo.br/pdf/pp/v19n3/v19n3a11>. Acesso em: 22 set. 2015.

LOURO, Guacira Lopes. Gênero, sexualidade e educação: Uma perspectiva pós-estruturalista. Petrópolis, RJ: Vozes, 1997.

PASSOS, Eduardo; KASTRUP, Virgínia; ESCÓSSIA, Liliana da (Orgs.). Pistas do método da cartografia: Pesquisa-intervenção e produção de subjetividade. Porto Alegre: Sulina, 2009.

PAZ, Cláudia Denis Alves da. Gênero no trabalho pedagógico da educação Infantil. ST. Educação Infantil e relações de gênero. In: SEMINÁRIO INTERNACIONAL FAZENDO GÊNERO - CORPO, VIOLÊNCIA E PODER, 8. 2008, Florianópolis. Anais eletrônicos... Florianópolis, 2008. Disponível 
em: <http://www.fazendogenero.ufsc.br/8/sts/ST10/Claudia_Denis_Alves_Paz_10.pdf>. Acesso em: 29 mar. 2015.

SOUZA, Fabiana Cristina de. Gênero e Infância: a noção de alteridade nas representações sociais de meninos e meninas. Educação e Linguagem. Ano 11, n. 18, p. 149-169, jul./dez, 2008. Disponível em: <https://www.metodista.br/revistas/revistas-ims/index.php/EL/article/viewFile/112/122>. Acesso em: 12 jun. 2015.

VIANNA, Claudia; FINCO, Daniela. Meninas e meninos da Educação Infantil: uma questão de gênero e poder. Cadernos Pagu. n. 33. Campina, jul./dez., 2009. Disponível em: <http://www.scielo.br/pdf/cpa/n33/10.pdf >. Acesso em: 13 mar. 2015.

VIANNA, Cláudia Pereira; GOMES, Lisandra Ogg. O que dizem as crianças sobre as questões de gênero. Revista Pátio Educação Infantil. Porto alegre, Ano XV, n. 36, p.8-11, jul./set, 2013. 
Do boys that play with dolls become girls? Gender differences in the play of 4-5 yearold children

\begin{abstract}
This text is derived from a study conducted for a final course project in pedagogy that focused on gender in early-childhood education. It sought to understand how children interact with toys brought from home or offered at school and examine if boys and girls choose different toys. Moreover, it investigates whether there is a relationship between toy colors and gender differences. We have adopted a qualitative approach, since we are interested in the singularity of children's expressions, movements and speech. We have used a cartographic methodology, which allows a sensitive listening and an attentive look at the territories to be investigated. Children's attitudes and reactions have been observed and recorded during school playtime, whether it was free or defined by the study. The research revealed that children do not propose marks of gender differences; but they emerge from the environment, particularly from parents and society in general. We also perceived that when this topic is discussed, children seem to understand and question the gender stereotypes seen in the context through toys. They also understand that playing is a free expression that does not have to be marked by gender stereotypes. Finally, we highlight that child education researchers should give more attention to gender studies, and everyone involved should discuss this theme more often.
\end{abstract}

Keywords: Gender. Child Education. Toys.

\section{¿Niños que juegan con muñecas se convierten en niñas? Diferencia de género en} los juegos de niños de 4 a 5 años

\section{Resumen}

En presente artículo buscó conocer como los niños interactúan con juguetes traídos de casa o presentes en la escuela, así también percibir si hay una diferencia en la elección de juguetes entre niños y niñas. Además, se investigó si habría relación entre los colores presentes en los juguetes y las diferencias de género. Se trata de un enfoque de naturaleza cualitativa, una vez que nos interesan las expresiones, movimientos y el habla de los niños en su singularidad. La metodología utilizada fue la cartográfica, que permite una escucha sensible, una mirada atenta en los territorios a ser investigados. Se realizaron observaciones y registros de las actitudes y reacciones de los niños en los momentos de juegos en la escuela, libres o definidos por la investigación. La búsqueda reveló que la diferencia de género no es una propuesta por los niños, pero sí por el medio en el que se encuentran, especialmente por los padres y por la sociedad en general. Se percibió que a partir del momento en que se coloca la temática en discusión, los niños y niñas parecen entender y cuestionar los estereotipos de género presentes en el contexto por medio de los juguetes. Se entiende que jugar es una expresión libre, que no necesita ser marcada por los estereotipos de género. Finalmente se destaca que los estudios de género merecen más atención por parte de los investigadores de la educación infantil y que la temática necesita ser más discutida por todos las personas que trabajan este tema.

Palabras clave: Género. Educación Infantil. Juguetes. 
Rafaela Junges

E-mail: rafaela_junges@ @otmail.com Suzana Feldens Schwertner

E-mail: suzifs@univates.br
Recebido em: 21/12//2015

Versão final recebida em: 05/09/2016 Aprovado em: 06/10/2016 